\title{
SISTEM PAKAR DIAGNOSA KERUSAKAN MESIN TRUCK DUTRO DENGAN METODE CERTAINTY FACTOR BERBASIS WEB
}

\author{
Muhamad Nizar ${ }^{1}$, Fitri Marisa ${ }^{2}$, Indra Dharma Wijaya ${ }^{3}$ \\ ${ }^{1}$ Fakultas Teknik, Jurusan Teknik Informatika, Universitas Widyagama Malang \\ ${ }^{2}$ Fakultas Teknik, Jurusan Teknik Informatika, Universitas Widyagama Malang \\ ${ }^{3}$ Fakultas Teknik, Jurusan Teknik Informatika, Universitas Widyagama Malang \\ Email: muhamadnyzar@yahoo.com
}

\begin{abstract}
Abstrak
Pada bidang trasportasi khususnya truk Dutro yang saat ini semakin banyak di minati banyak user atau customer truk yang masih sangat awam mengenai pengetahuan kendaraan, sehingga mereka sering mengeluhkan tentang unit mereka saat mengalami kerusakan, dikarenakan kurangnya pengetahuan berakibat terjadi kesalahan perbaikan yang tidak sesuai dengan kerusakan, sehingga user harus mengeluarkan biaya yang lebih karena kesalahan pada analisa kerusakan. Permasalahan pengambilan keputusan dapat menjadi kompleks karena adanya beberapa tujuan maupun kriteria. Aplikasi ini di bangun menggunakan Bahasa pemprogaman Php untuk medesain tampilan dan untuk perhitungan analisa mengguanakan metode Certainty factor, dari aplikasi ini pengguna dapat memilih gejala yang dialamai agar aplikasi dapat melakukan proses pencarian dan perhitungan sesuai gejala yang di timbulkan sehingga dapat memberikan kesimpulan keruskan dan solusi untuk melakukan perbaikan unit truck dutro mereka.
\end{abstract}

Kata Kunci: Gejala kerusakan, Kerusakan Truck Dutro, Certainty Factor

\begin{abstract}
In the field of transportation, especially Dutro trucks, which are currently increasingly attracted by many users or truck customers who are still very unfamiliar with the knowledge of vehicles, they often complain about their units when they are damaged, because lack of knowledge results in errors in repairs that do not match damage so that the user has to spend more because of an error in the damage analysis. Decision-making problems can be complex because of several goals and criteria. This application was built using PHP programming language to design the display and for analysis calculations using the Certainty factor method, from this application the user can choose the symptoms experienced so that the application can perform the search process and calculations according to the symptoms caused so that it can provide conclusions and solutions to repair their Dutro truck units.
\end{abstract}

Keywords: Application objectives, symptoms of damage, Dutro Truck Damage, Certainty Factor 


\section{PENDAHULUAN}

Saat ini kendaraan merupakan kebutuhan yang sangat penting bagi kehidupan manusia. Selain sebagai transportasi bagi pengguna kendaraan juga dapat di gunakan sebagai media angkutan barang atau penumpang dari suatu tempat ke tempat lain. Jenis kendaraan salah satunya adalah truk. Truk merupakan sebuah kendaraan yang di gunakan untuk memenuhi kebutuhan bidang akutan barang di karenakan memiliki kuatitas daya angkut yang besar, di Indonesia sendiri sudah banyak masyarakat yang memiliki alat transportasi truck. Truck juga banyak dimanfaatkan sebagai media angkutan barang dalam Kota maupun pertambangan pasir dalam medistribusikan suatu barang.

Banyak oarang yang mengunakan kendaraan truk karenakan memiliki type kuatitas yang dapat di sesuaikan dengan kebutuhan daya angkut mereka. Banyaknya kegunaan dari truk ini maka tidak menutup kemungkinan setiap kendaraan yang digunakan pasti akan mengalami kerusakan baik itu kerusakan ringan yang dapat diperbaiki sendiri atau kerusakan berat yang harus diperbaiki oleh ahlinya, oleh karena itu membutuhkan sistem yang dapat mendeteksi kerusakan pada truk. Sistem tersebut yaitu sistem pakar diagnosa kerusakan truk dutro.

Penguna pemula dan para awam sering kali mengalami kesulitan dalam mentukan kerusakan yang terjadi pada unit mereka. Belum lagi tentang adanyan kerusakan yang terjadi secara mendadak pada unit truck yang kurang pengetahuan customer untuk menanganinya sehingga sering terjadi kerusakan yang lebih fatal. Karena banyak type kerusakan yang terjadi pada truck maka di perlukan seorang pakar yang di harapkan dapat memberikan pengetahuan cara penanganan kerusakan yang dapat di akses dengan muda oleh masyarakat luas.

Dari masalah diatas di harapkan adanya suatu sistem yang dapat membatu customer atau user dalam penanganan kerusakan pada unit truck mereka. Sehingga cutomer dapat memperbaiki kerusakan unit mereka dengan tepat adalah sistem pakar, sistem pakar merukapan sistem yang di buat berdasarkan keahlian seorang pakar atau seseoarang yang ahli dalam menjawab suatu masalah yang terjadi.

\section{STUDI PUSTAKA}

\section{$2.1 \quad$ Sistem pakar}

Sistem pakar adalah aplikasi berbasis komputer yang digunakan untuk menyelesaikan masalah sebagaimna yang dipikirkan oleh pakar. Pakar yang dimaksud yang dimaksud adalah orang yang mempunyai keahliah khusus yang dapat menyelesaikan masalah yang tidak dapat diselesaikan oleh orang awam [1] Sebagai contoh adalah dokter seorang pakar yang mampu mendiagnosis penyakit yang diderita penyakit tersebut.

Sistem pakar merupakan cabang dari Artificial Intelligent (AI) yang cukup tua karena sistem ini mulai dikembangkan pada pertengahan tahun 1960. Sistem pakar yang muncul pertama kali adalah General -Purpose problem solver (GPS) yang dikembangkan oleh Newel dan Simon [2]. Sampai saat ini sudah banyak sistem pakar yang dibuat, seperti untuk diagnosis penyakit, mengidentifikasi structural molekul campuran yang tak dikenal, untuk membantu konfigurasi sistem komputer besar, untuk analisis sirkuit elektronik, prespoctor digunakan di bidang geologi untuk membantu mencari dan menemukan deposit, untuk memberikan bagi seorang manajer dalam stok investasi, untuk pemeliharaan lokomotif listrik diesel, dan sebagainya [3]. 


\subsection{Difinisi sistem pakar (Expert Sytem)}

Sistem pakar atau Expert System biasa disebut juga dengan knowledge based system yaitu suatu aplikasi komputer yang ditujukan untuk membantu pengambilan keputusan atau pemecahan persoalan dalam bidang yang spesifik. Sistem ini bekerja dengan menggunakan pengetahuan (knowledge) dan metode analisis yang telah didefinisikan terlebih dahulu oleh pakar yang sesuai dengan bidang keahliannya. Sistem ini disebut sistem pakar karena fungsi dan perannya sama seperti seorang ahli yang harus memiliki pengetahuan, pengalaman dalam memecahkan suatu persoalan. Sistem biasanya berfungsi sebagai kunci penting yang akan membantu suatu sistem pendukung keputusan atau sistem pendukung eksekutif sedangkan pengertian system pkar menurut para ahli adalah sebahai berikut:

a. Menurut Durkin : Sistem pakar adalah suatu program computer yang di rancang untuk memodelkan kemampuan penyelesaian masalah yang di lakukan oleh seorang pakar.

b. Menurut Ignizio : Sistem Pakar adalah suatu model atau prosedur yang berkaitan, dalam suatu domain tertentu yang mana tingkat keahliannya dapat dibandingkan dengan keahlian seorang pakar [2].

\subsection{Ciri - ciri sistem pakar}

Suatu sistem dikatakan pakar apabila mempunyai ciri - ciri sebagai berikut:

a. Terbatas pada domain keahlian tertentu.

b. Dapat memberikan penalaran untuk data - data yang tidak pasti.

c. Dapat mengemukakan rangkaian alasan - alasan yang diberikan dengan cara yang dapat dipahami.

d. Berdasarkan pada kaidah atau rule tertentu.

e. Dirancang untuk dikembangkan secara bertahap.

f. Keluarannya atau output bersifat anjuran [4].

\subsection{Mertode Certainty factor}

Faktor kepastian (certainty factor) diperkenalkan oleh Shortliffe Buchanan dalam pembuatan MYCIN. MYCIN merupakan program interaktif yang melakukan diagnosis penyakit miningitis dan infeksi bacrenia serta memberikan rekomendasi terapi anti mikrobia.Certainty factor $(\mathrm{CF})$ merupakan nilai parameter klinis yang diberikan MYCIN untuk menunjukkan besarnya kepercayaan. Dalam teori kepastian

(Certainty Theory), sama halnya dengan fuzzy logic, ketidakpastian direpresentasikan dengan derajat kepercayaan [5]. Terdapat 2 langkah dalam penggunaan setiap metode nonprobabilitas. Pertama, perlunya dapat mengekspresikan derajat kepercayaan. Kedua, perlunya untuk memanipulasi (mengkombinasi) derajat dari kepercayaan ketika menggunakan knowledge-based systems. Certainty Factor mengekspresikan kepercayaan dalam kejadian (atau fakta atau hipotesis) berdasarkan kejadian (atau pada penilaian seorang pakar). Ada beberapa metode dari penggunaan Certainty Factor untuk menangani ketidakpercayaan dalam knowledge-based systems [1]. Salah satu cara dengan menggunakan 1.0 atau 100 untuk kepercayaan absolut (keyakinan penuh) dan 0 untuk kesalahan yang pasti. Certainty factor didefenisikan sebagai berikut:

$$
\mathrm{CF}(\mathrm{H}, \mathrm{E})=\mathrm{MB}(\mathrm{H}, \mathrm{E})-\mathrm{MD}(\mathrm{H}, \mathrm{E})
$$


Keterangan:

$\mathrm{CF}(\mathrm{H}, \mathrm{E})$ : certainty factor dari hipotesis $\mathrm{H}$ yang dipengaruhi oleh gejala $\mathrm{E}$ (evidence). Besarnya CF berkisar antara -1 sampai 1. Nilai -1 menunjukkan ketidakpercayaan mutlak, sedangkan nilai 1 menunjukkan kepercayaan mutlak.

MB (H, E) : ukuran kepercayaan (measure of increased belief) terhadap hipotesis $\mathrm{H}$ yang dipengaruhi oleh gejala $\mathrm{E}$.

$\mathrm{MD}(\mathrm{H}, \mathrm{E}) \quad$ : ukuran ketidakpercayaan (measure of increased disbelief) terhadap hipotesis $\mathrm{H}$ yang dipengaruhi oleh gejala $\mathrm{E}$.

a. Menggunakan Metode 'Net Belief'

Tingkat keyakinan (CF) dalam metode net belief dapat dihitung dengan rumus sebagai berikut:

$$
\begin{aligned}
& \mathrm{CF}(\mathrm{RULE})=\mathrm{MB}(\mathrm{H}, \mathrm{E})-\mathrm{MD}(\mathrm{H}, \mathrm{E}) \\
& M B(H \mid E)=\left\{\begin{array}{c}
1 \\
\frac{M A X[P(H \mid E), P(H)]-P(H)}{1-P(H)}
\end{array}\right. \\
& M D(H \mid E)=\left\{\begin{array}{c}
1 \\
\frac{M I N[P(H \mid E), P(H)]-P(H)}{1-P(H)}
\end{array}\right.
\end{aligned}
$$

Keterangan:

$\mathrm{MB}(\mathrm{H}, \mathrm{E}) \quad=$ Ukuran kepercayaan (Measure of Increased Belief) terhadap hipotesis $\mathrm{H}$ yang dipengaruhi oleh Evidence E

$\mathrm{MD}(\mathrm{H}, \mathrm{E}) \quad=$ Ukuran ketidakpercayaan (Measure of Increased Disbelief) terhadap hipotesis $\mathrm{H}$ yang dipengaruhi oleh Evidence $\mathrm{E}$

$\mathrm{P}(\mathrm{H}) \quad=$ Probabilitas kebenaran hipotesa $\mathrm{H}$

$\mathrm{P}(\mathrm{H} \mid \mathrm{E}) \quad=$ Probabilitas bahwa $\mathrm{H}$ benar karena fakta $\mathrm{E}$

$\mathrm{P}(\mathrm{H})$ dan $\mathrm{P}(\mathrm{H} \mid \mathrm{E})$ merepresentasikan keyakinan dan ketidakyakinan pakar. Untuk menghitung nilai $\mathrm{P}(\mathrm{H} \mid \mathrm{E})$ nantinya akan menggunakan Probabilitas Bayesian.

b. Dengan menggali dari hasil wawancara dengan pakar

c. Dengan menggali dari hasil wawancara dengan pakar. Nilai CF didapat dari interpretasi term dari pakar menjadi nilai MD atau MB tertentu. Yang di gunakan untuk menghitung nilai $\mathrm{CF}$ dari suatu rule dengan beberapa metode [1].

\subsection{Proses perhitungan CF (certainty factor)}

Proses ini di gunakan oleh user untuk memasukan gejalah yang ada pada system sesuai gejala yang timbul, apabila user hanya menginputkan 1 gejalah akan dilakukan perhitungan Certainty Factor $(\mathrm{CF})$ dengan menghitung MB (measure of increased belief terhadap nilai Kerusakan truck) - MD (measure of increased disbelief terhapad kerusakan truk). Dan apabila user menginputkan atau memilih daftar gejalah lebih dari 1 maka proses perhitungan akan di lakukan dengan Cara:

1. Hitung MB dan MD sementara kemudian menghasilkan CF sementara

2. Hitung MB dan MD baru

3. Hitung CF Hasil dengan rumus MB baru - MD baru 
4. Dari perhitungan diperoleh hasil diagnosa dan nilai certainty factor [6].

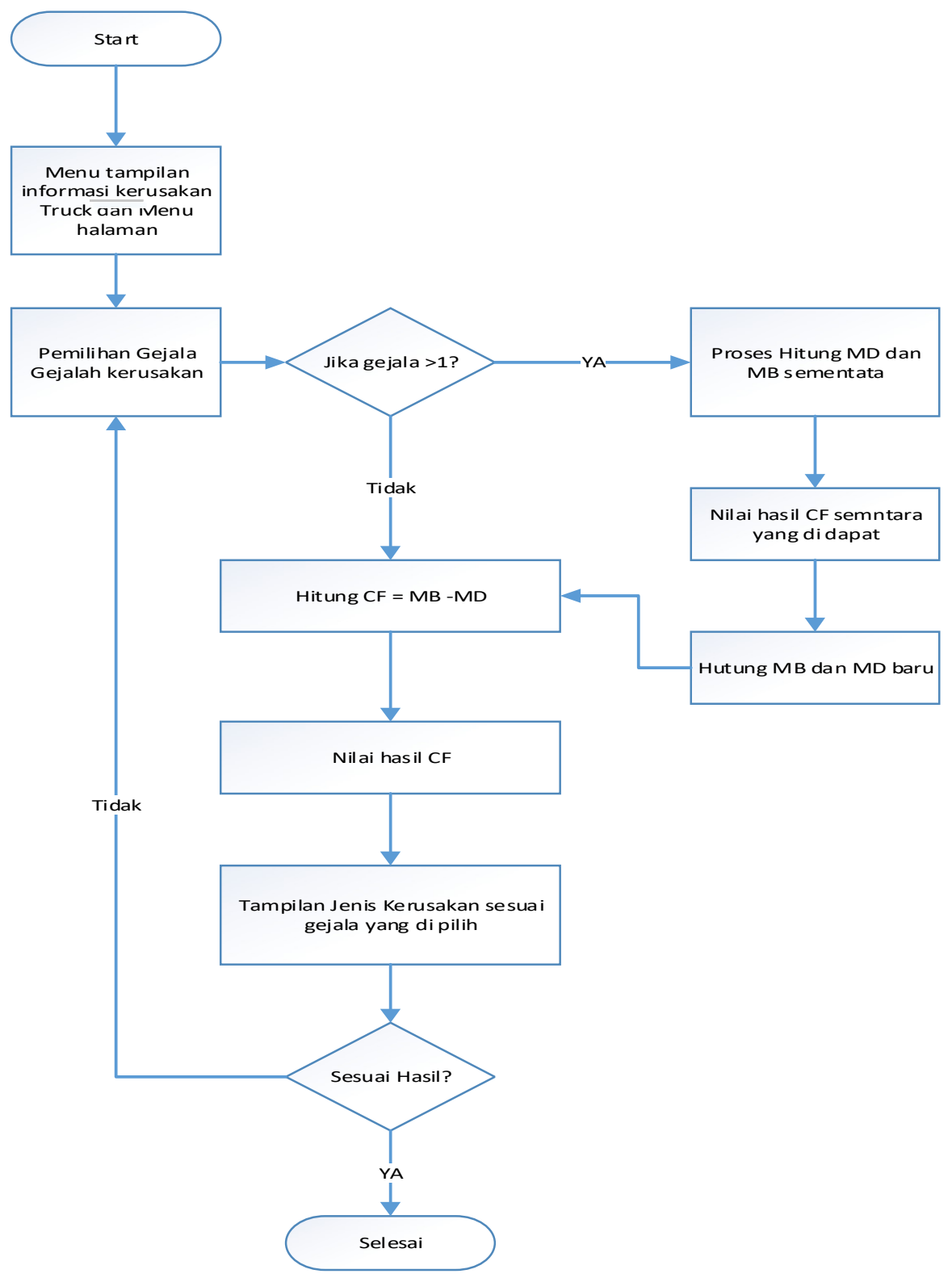

Gambar 2.1 Flowchart metode certainty factor

\section{METODE}

\subsection{Metode Penelitian}




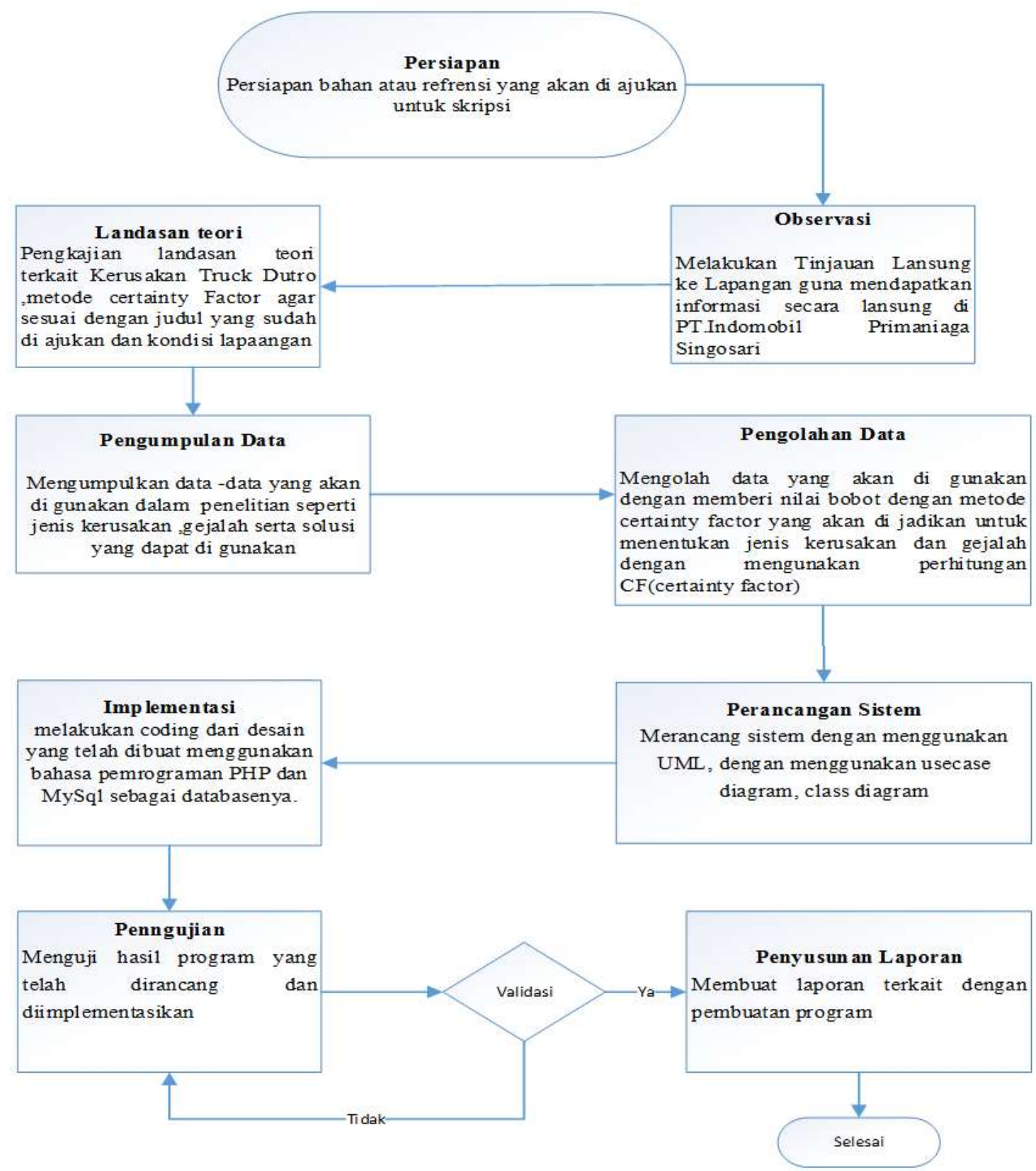

Gambar 3.1: Bagan Metodologi Penelitian

\subsubsection{Persiapan}

Pada tahap ini yaitu mempersiapkan bahan atau referensi untuk pengajuan penelitian yang akan diambil 


\subsubsection{Observasi}

Melakukan Tinjauan Lansung ke Lapangan guna mendapatkan informasi secara lansung di PT.Indomobil Primaniaga Singosari

\subsubsection{Pengumpulan Data}

Tahapan Pertama dalam penelitian ini adalah pengumpulan data. Pengumpulan data dilakukan terlebih dahulu agar bisa mendapatkan data-data dan informasi terkait dengan sistem pakar untuk melakukan pencarian terhadap kerusakan Truck dengan metode Certainty factor. Adapun teknik pengumpulan data yang dilakukan observasi dan studi pustaka.

Pegumpulan data dilakukan dengan cara wawancara atau konsultasi secara langsung kepada Foreman Atau Mekanik yang merupakan pakar, dalam hal ini para pkar memberikan data-data yang di butuhkan berkaitan dengan perancangan sistem pakar.

\subsubsection{Pengolahan Data}

Pengolahan Data dilakukan Setelah data terkumpul data akan diolah untuk menentukan gejala, jenis jenis kerusakan dan menghitung bobot gejala tersebut menggunakan metode certainty factor. Tahap 1

Pengolahan data dibagi menjadi 3 tahap yaitu:

Tahapan awal yang dilakukan adalah mendefinisikan gejala kerusakan truck dutro yang disusun berdasarkan struktur hirarki. Tahapan ini disebut juga tahapan perancangan input data, hasil pendefinisian unsur-unsur gejala.

Tahap 2

Tahapan ini merupakan tahap untuk melakukan proses dari data yang telah disimpan pada tahap sebelumnya. Tahapan ini dibagi menjadi dua bagian yaitu proses untuk melakukan penilaian dari masing-masing unsur penilaian. Proses tersebut terdiri dari.

a. Menghitung bobot dari setiap unsur penilaian, melalui penjumlahan dari masing-masing unsur yang ditetapkan.

b. Menghitung total bobot gejala dari masing-masing unsur penilaian yang telah diperoleh dari tiap-tiap unsur.

c. Melakukan pendefinisian dari hasil akhir total bobot gejala yang telah diperoleh User.

Tahap 3

Tahap ini merupakan tahap output dari hasil proses data, hasil kalkulasi yang telah dilakukan dan disimpan di basis data untuk ditampilkan ke User agar mudah dipahami.

\section{HASIL DAN PEMBAHASAN}

\subsection{Basis pengetahuan}


Basis pengetahuan dalam aplikasi ini berisi tentang jenis kerusakan pada truck dutro dan gejala-gejala yang timbul serta solusi yang di lakukan ketika unit mengalami kerusakan,

a. Jenis kerusakan

Tabel 3.1 jenis kerusakan

\begin{tabular}{|c|l|}
\hline Kode & \multicolumn{1}{|c|}{ Jenis Kerusakan } \\
\hline K 01 & Batery drop \\
\hline K 02 & Motor stater aus \\
\hline K 03 & Filter udara kotor \\
\hline K 04 & Radiator bocor \\
\hline K 05 & Air Radiator Habis \\
\hline K 06 & Filter bahan bakar kotor atau terjadi kebocoran pada fuel line \\
\hline K 07 & Kampas Kopling Aus \\
\hline
\end{tabular}

b. Jenis gejala

Tabel 3.2 jenis gejala

\begin{tabular}{|c|l|}
\hline Kode & \multicolumn{1}{|c|}{ Gejala } \\
\hline G01 & Mesin tidak bisa di stater \\
\hline G02 & $\begin{array}{l}\text { Stater menyalah tapi tidak kuat memutar mesin dan } \\
\text { mengeluarkan bunyi ketukan secara cepat }\end{array}$ \\
\hline G03 & Berat saat di stater \\
\hline G04 & Mesin tidak bisa di stater Stater mesin berbunyi "klik-klik \\
\hline G05 & Tenaga mesin berkurang atau low power \\
\hline G06 & Indicator tekanan air menyalah \\
\hline G07 & Air radiator berkurang setiap beberapa saat \\
\hline G08 & Mesin overheating \\
\hline G09 & Keluar Uap Asap pada saat tutup radiator di buka \\
\hline G10 & Mesin TIdak Dapat mencapai putara tinggi \\
\hline G11 & Mesin mati secara perlahan pada saat mesin berputar \\
\hline G12 & Unit tidak bisa berjalan \\
\hline G13 & Gigi Transmisi susah masuk \\
\hline G14 & Terjadi Noise pada Saat pedal kopling di injak \\
\hline
\end{tabular}

c. Jenis solusi dan kerusakan

Tabel 3.3 kerusakan, gejala, dan solusi unit 


\begin{tabular}{|c|c|c|}
\hline $\begin{array}{c}\text { Jenis } \\
\text { Kerusakan }\end{array}$ & Gejala & Solusi \\
\hline Batery drop & $\begin{array}{l}\text { - Mesin tidak bisa di } \\
\text { stater } \\
\text { - Stater menyalah tapi } \\
\text { tidak kuat memutar } \\
\text { mesin dan } \\
\text { mengeluarkan bunyi } \\
\text { ketukan secara cepat }\end{array}$ & $\begin{array}{l}\text { - Periksa level air baterty secara periodical apabila } \\
\text { di garis minimum segera tambahkan air battery } \\
\text { - Periksa tegangan battery } \\
\text { - Periksa kekecangan sambungan terminal battery } \\
\text { yang terhubung ke motor stater } \\
\text { - Periksa ujung terminal positif dan negative } \\
\text { apabila kotor segera bersikah }\end{array}$ \\
\hline $\begin{array}{l}\text { Motor stater } \\
\text { aus }\end{array}$ & $\begin{array}{l}\text { - Mesin tidak bisa di } \\
\text { stater } \\
\text { - Berat saat di stater } \\
\text { - Mesin tidak bisa di } \\
\text { stater } \\
\text { - Stater mesin berbunyi } \\
\text { "klik-klik }\end{array}$ & $\begin{array}{l}\text { - Periksa sambungan arus dari battery ke motor } \\
\text { stater } \\
\text { - Check komponen yang berhungan dengan motor } \\
\text { stater seperti kunci kontak apa ada arus yang } \\
\text { masuk atau tidak } \\
\text { - Lakukan overhaul pembongkaran untuk } \\
\text { pengecekan dynamo stater apakah komponen } \\
\text { dalem aus seperti rotor stater,brush karbon,atau } \\
\text { solenoid stater }\end{array}$ \\
\hline $\begin{array}{l}\text { Filter udara } \\
\text { kotor }\end{array}$ & $\begin{array}{l}\text { - Tenaga mesin } \\
\text { berkurang atau low } \\
\text { power }\end{array}$ & $\begin{array}{l}\text { - lakukan peyemprotan filter udara setiap } 2000 \mathrm{~km} \\
\text { atau semprot apabila sudah terlalu kotor } \\
\text { (tergantung medan jalan) } \\
\text { - ganti filter udara setiap 40.000km dengan medan } \\
\text { normal dan } 20.000 \text { dengan kemedan berdebu }\end{array}$ \\
\hline $\begin{array}{l}\text { Radiator } \\
\text { bocor }\end{array}$ & $\begin{array}{l}\text { - Indicator tekanan air } \\
\text { menyalah } \\
\text { - Air radiator berkurang } \\
\text { setiap beberapa saat }\end{array}$ & $\begin{array}{l}\text { - Periksa posisi tutup radiator apa sudah pas atau } \\
\text { belum } \\
\text { - Periksa komponen radiataor yang terhubung } \\
\text { seperti selang radiator apa clam selang sudah } \\
\text { rapat atau belum } \\
\text { - Ganti selang radiator apabila terjadi kebocoran } \\
\text { - Check air radiator apabila bertekanan ganti } \\
\text { gasket cylinder head di karenakan gasket } \\
\text { mengalami kerusakan }\end{array}$ \\
\hline $\begin{array}{l}\text { Air radiator } \\
\text { habis }\end{array}$ & $\begin{array}{l}\text { - Indicator tekanan air } \\
\text { menyalah } \\
\text { - Mesin overheating } \\
\text { - Keluar uap asap dari } \\
\text { pada saat tutup radiator } \\
\text { di buka }\end{array}$ & $\begin{array}{l}\text { - Matikan mesin apabila indicator tekanan air } \\
\text { menyalah } \\
\text { - Tunggu hingga mesin suhu normal kemudian isi } \\
\text { kembali air radiator } \\
\text { - Check sumber kebocoran pada radiator } \\
\text { - Lakukan perbaikan atau pengantian komponen } \\
\text { apabila sumber kebocoran sudah di temukan }\end{array}$ \\
\hline $\begin{array}{l}\text { Filter bahan } \\
\text { bakar kotor } \\
\text { atau terjadi } \\
\text { kebocoran } \\
\text { pada fuel } \\
\text { line }\end{array}$ & $\begin{array}{l}\text { - Mesin tidak dapat } \\
\text { mencapai putaran tinggi } \\
\text { - Mesin low power } \\
\text { - Mesin mati secara } \\
\text { perlahan pada saat } \\
\text { mesin berputar }\end{array}$ & $\begin{array}{l}\text { - Lakukan pembersihan filter bahan bakar di } \\
\text { rekomendasikan ganti filter dengan yang baru } \\
\text { - Check tangki bahan bakar apabila kotoran di } \\
\text { temukan pada filter yang baru } \\
\text { - Kuras tangki bahan bakar untuk memastikan } \\
\text { kebersihan bahan bakar } \\
\text { - Check kebocoran fuel line apakah terdapat } \\
\text { kebocoran sehingga memgakibatkan tercampur } \\
\text { ya bahan bakar dan udara atau dengan air } \\
\text { mengakibat kan mesin up normal } \\
\text { - Bleding atw keluarkan udara atw air dari fuel } \\
\text { sistem karena dapat menyebabkan engine low } \\
\text { power dan mati secara perlahan ataupun susah } \\
\text { start. }\end{array}$ \\
\hline $\begin{array}{l}\text { Kampas } \\
\text { kopling aus }\end{array}$ & $\begin{array}{l}\text { - Mesin low power } \\
\text { - Unit tidak bisa jalan } \\
\text { - Gigi transmisi susah } \\
\text { masuk } \\
\text { - Noise saat pedal kopling } \\
\text { di injak }\end{array}$ & $\begin{array}{l}\text { - Stel ketinggian pedal kopling } \\
\text { - Ganti kampas kopling }\end{array}$ \\
\hline
\end{tabular}

4.2 Ralasi kerusakan truk tehadap gejala 
Gejala yang timbul pada satu kerusakan dapat juga terjadi pada kerusakan lainya yang juga mengakibatkan kerusakan pada unit truk dutro dan untuk memudahkan maka di buat tabel keruskan truk berdasarkan gejala seperti tabel 3.4.

Tabel 3.4 Kerusakan truk Dutro berdasarkan gejala

\begin{tabular}{|l|c|}
\hline \multicolumn{1}{|c|}{ Jenis Kerusakan } & Kode \\
\hline \multirow{2}{*}{ Batery Drop } & G01 \\
& G02 \\
Motor Stater Aus & G01 \\
\hline Filter Udara Kotor & G03 \\
& G04 \\
\hline \multirow{2}{*}{ Radiator Bocor } & G05 \\
& G11 \\
\hline \multirow{2}{*}{ Air Radiator Habis } & G06 \\
& G07 \\
\hline \multirow{2}{*}{ Filter bahan bakar kotor atau terjadi kebocoran } & G08 \\
pada fuel line & G06 \\
& G08 \\
& G09 \\
\hline & G01 \\
Kampas Kopling Aus & G10 \\
& G11 \\
\hline
\end{tabular}

\subsubsection{Nilai Bobot penentuan Nilai Cf}

Proses aturan ini bertujuan untuk menentukan pencarian atau menentukan kesimpulan dari Kerusakan Truck Dutro. Hasil dari wawancara kepada pakar (mekanik dan Foreman) pada hari Senin, 10 September 2018. Di Pt Indomobil Primaniaga Singosari. Mendapatkan hasil berupa nilai bobot pada setiap kerusakan berdasarkan gejalah yang ada ditunjukkan seperti pada tabel berikut:

Tabel 3.5 Nilai bobot

\begin{tabular}{|c|c|c|c|c|c|c|c|c|c|c|c|c|c|c|}
\hline \multirow{3}{*}{$\begin{array}{l}\text { Kode } \\
\text { Gejala }\end{array}$} & \multicolumn{14}{|c|}{ Kode Kerusakan Truck dutro } \\
\hline & \multicolumn{2}{|c|}{ K01 } & \multicolumn{2}{|c|}{ K02 } & \multicolumn{2}{|c|}{ K03 } & \multicolumn{2}{|c|}{ K04 } & \multicolumn{2}{|c|}{ K05 } & \multicolumn{2}{|c|}{ K06 } & \multicolumn{2}{|c|}{ K07 } \\
\hline & MD & MB & MD & MB & MD & MB & MD & MB & MD & MB & MD & MB & MD & MB \\
\hline G1 & 0,2 & 0,7 & 0,2 & 0,8 & 0,8 & 0,2 & 0,8 & 0,1 & 0,7 & 0,2 & 0,2 & 0,5 & $0 ., 9$ & 0,2 \\
\hline G2 & 0,2 & 0,7 & 0,2 & 0,3 & 0,9 & 0,1 & 0,1 & 0,2 & 0,8 & 0,1 & 0,8 & 0,2 & 0,8 & 0,1 \\
\hline G3 & 0,2 & 0,7 & 0,2 & 0,7 & 0,7 & 0,2 & $0 ., 7$ & 0,1 & 0,3 & 0,2 & 0,8 & 0,2 & 0,7 & 0,1 \\
\hline G4 & 0,3 & 0,2 & 0,2 & 0,7 & 0,5 & 0,1 & 0,7 & 0,1 & 0.8 & 0,1 & 0,9 & 0,1 & 0,8 & 0,2 \\
\hline G5 & 0,3 & 0,2 & 0,3 & 0,2 & 0,2 & 0,7 & 0,4 & 0,2 & 0,3 & 0,1 & 0,2 & 0,6 & 0,2 & 0,6 \\
\hline G6 & 0,9 & 0,2 & 0,9 & 0,2 & 0,9 & 0,1 & 0,2 & 0,7 & 0,2 & 0,9 & 0.8 & 0,1 & 0,9 & 0,1 \\
\hline G7 & 0,7 & 0,2 & 0,7 & 0,2 & 0,8 & 0,1 & 0,2 & 0,8 & 0,7 & 0,2 & 0,9 & 0,1 & 0,9 & 0,1 \\
\hline G8 & 0,7 & 0,2 & 0,4 & 0,2 & 0,2 & 0,3 & 0,2 & 0,7 & 0,2 & 0,8 & 0,2 & 0,4 & 0,8 & 0,2 \\
\hline G9 & 0,7 & 0,2 & 0,9 & 0,2 & 0,8 & 0,1 & 0,3 & 0,2 & 0,2 & 0,7 & 0,8 & 0,1 & 0,9 & 0,1 \\
\hline G10 & 0,5 & 0,3 & 0,3 & 0,2 & 0,2 & 0,6 & 0,7 & 0,2 & 0.8 & 0,2 & 0,2 & 0,5 & 0,5 & 0,2 \\
\hline G11 & 0,5 & 0,2 & 0,2 & 0,3 & 0,3 & 0,2 & 0,7 & 0,1 & 0,3 & 0,2 & 0,2 & 0,8 & 0,6 & 0,2 \\
\hline G12 & 0,1 & 0,2 & 0,7 & 0,1 & 0,3 & 0,2 & 0,7 &, 1 & 0,2 & 0,3 & 0,9 & 0,2 & 0,2 & 0,7 \\
\hline G13 & 0,9 & 0,1 & 0,9 & 0,1 & 0.9 & 0,1 & 0,9 & 0,1 & 0,9 & 0,1 & 0,9 & 0,1 & 0,2 & 0,8 \\
\hline G14 & 0,9 & 0,1 & 0,9 & 0,1 & 0,9 & 0,1 & 0,9 & 0,1 & 0,9 & 0,1 & 0,9 & 0,1 & 0,2 & 0,7 \\
\hline
\end{tabular}

Keterangan:

MB = adalah nilai kepercayaan yang di berikan oleh pakar

$\mathrm{MD}=$ adalah nilai ketidakpercayaan 
Dan untuk tanda kuning adalah relasi kerusakan yang berhubungan antara kerusakan dan gejala yang timbul seperti yang di jelaskan pada tabel 3.4

\subsection{Tampilan Program}

\subsubsection{Halaman utama User}

Halaman ini merupakan halaman awal ketika user membuka aplikasi, halaman ini menampilkan beberapa menu yaitu :

a. Halaman dashboard user menampilan menu untuk memulai quiz atau analisa untuk melakukan perhitungan berdasarkan gejala yang ada

b. Pada menu di samping bergambar truck user juga dapat melihat beberapa jenis kendaraan truck hino dutro dan spesifikasinya.

Berikut tampilan dashboard awal untuk menu User yang terdapat pada gambar 3.2

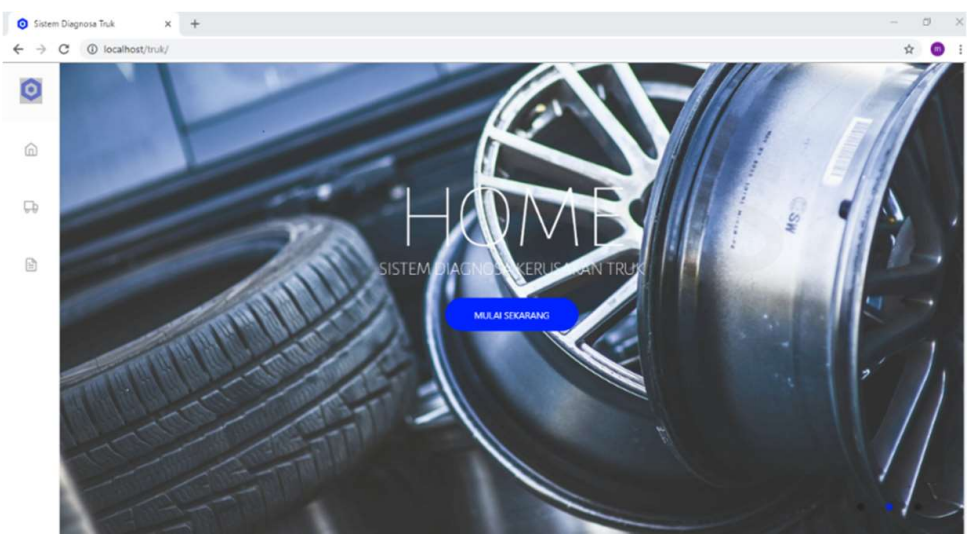

Gambar 3.2 halaman utama (index)

\section{Halaman Analisa Quiz}

Halaman ini terdapat form pengisian biodata user secara singkat sebelum user dapat meggunakan analisa kerusakan atau pemilihan Gejala.

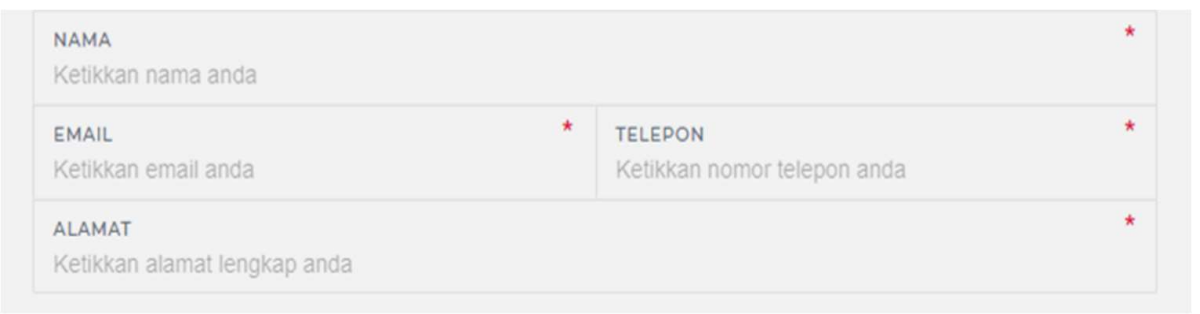

Gambar 3.3 halaman pengisian biodata user

Setelah user melalukan pengisian biodata user dapat memilih gejala yang ada dengan mecentang gejala untuk menentukan kerusakan yang akan terjadi dan klik simpan. 


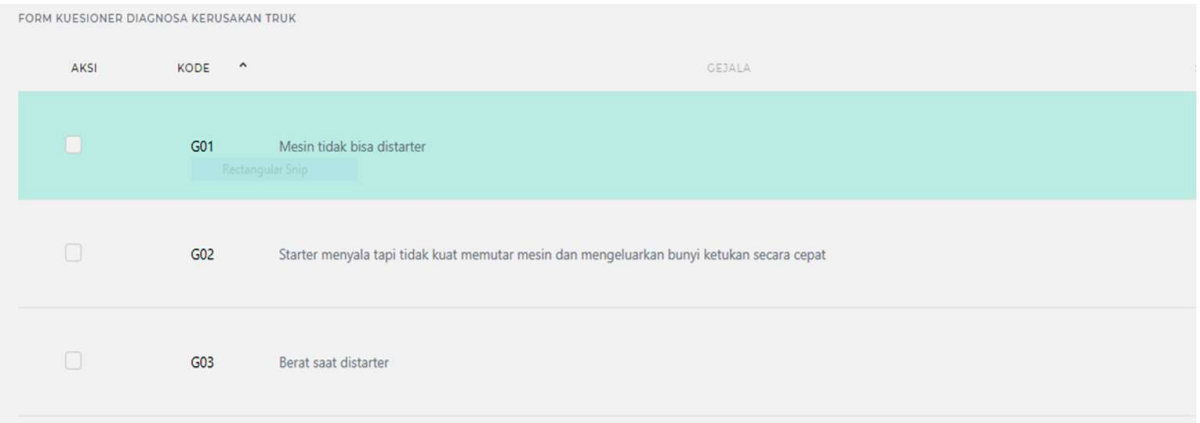

Gambar 3.4 halaman pemilhan gejala.

\section{Halaman Hasil}

Halaman ini menampilan data user dan hasil dari kesimpulan analisa kerusakaan terhadap gejala yang sudah di pilih.

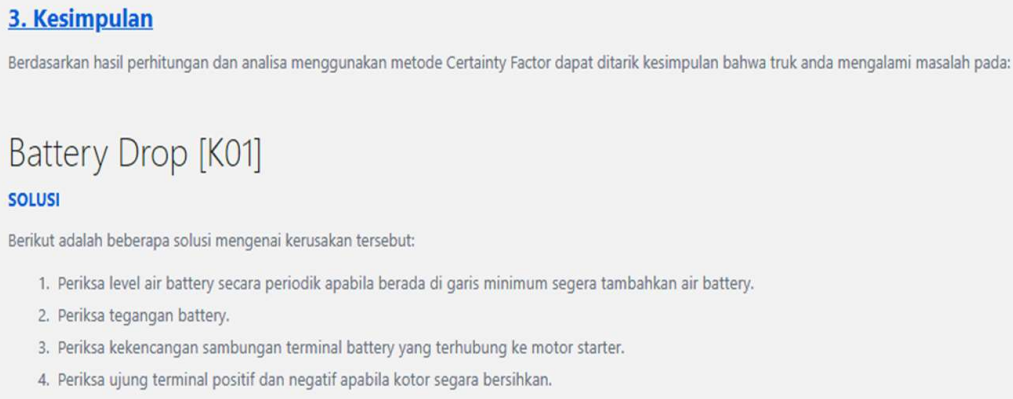

Gambar 3.5 hasil kesimpulan

\section{Halaman Log in Admin}

Halaman ini adalah halaman awal pada saat admin mau masuk dan admin wajib di menginputkan username dan password agar dapat masuk dan melakukan input,delete, dan update data.
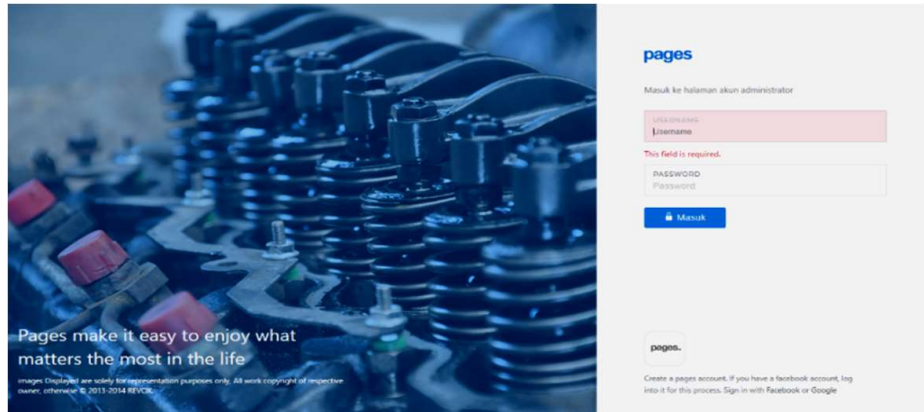

Gambar 3.6 halaman Login admin

4. Halaman dashboard Admin

Halaman ini adalah halaman utama admin yang berisi dari beberapa halaman antara lain Data Histori pengguna,Data Truck,Data kerusakan ,Data Gejala,Data 
Solusi,Data pengetahuan dan ada juga Data akun dan spanduk untuk menginputkan tampilan pada menu user, di tunjukan pada gambar 3.7

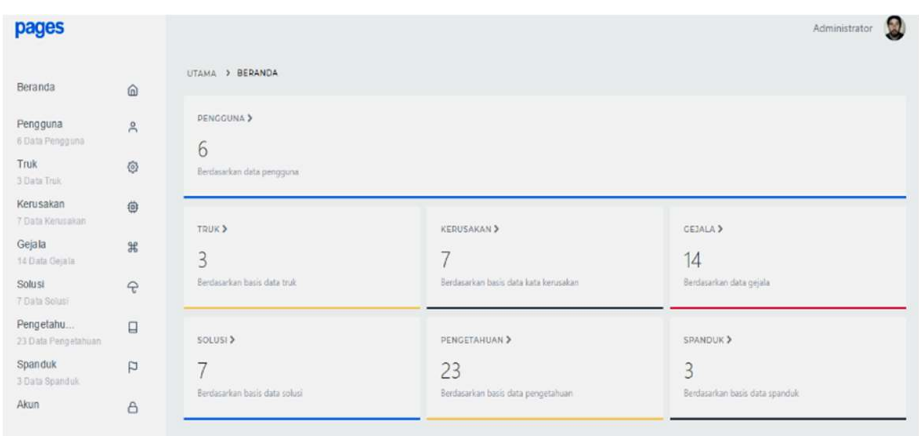

Gambar 3.7 Halaman Dashboard Admin

\subsection{Hasil Pengujian diagnose}

\subsection{1 inisialisasi gejala}

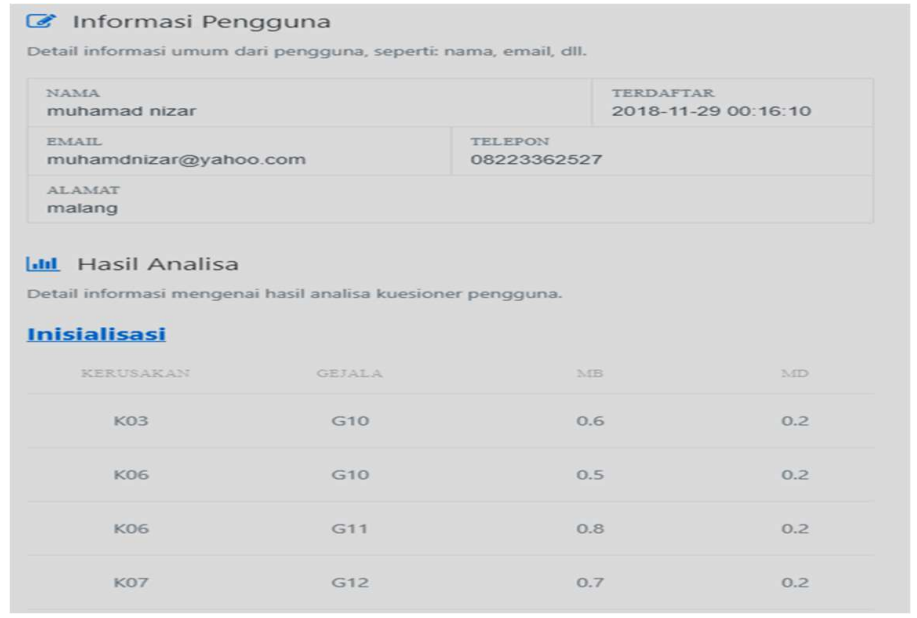

Gambar 3.8 hasil inisialisasi

Pada gambar ini menjelaskan inisialisasi terhadap gejala yang telah di pilih oleh user dan pengelolahan data yang sudah sesuai dengan tabel relasi kerusakan.

\subsubsection{Analisa Kerusakan}

Di ketahui sebuah unit memiliki 3 gejala kerusakan, gejala tersebut di ketahui terdapat pada 3 kerusakan pada tabel irisan:

Tabel 3.6 Contoh kerusakan

\begin{tabular}{|l|l|l|c|c|}
\hline Nama kerusakan & $\begin{array}{c}\text { Kode } \\
\text { Gejala }\end{array}$ & \multicolumn{1}{|c|}{ Gejala yang dipilih } & $\begin{array}{c}\text { Nilai } \\
\text { MB }\end{array}$ & $\begin{array}{c}\text { Nilai } \\
\text { MD }\end{array}$ \\
\hline Filter udara kotor & G10 & Mesin tidak dapat mencapai putaran tinggi & 0,6 & 0,2 \\
\hline Filter solar kotor & G10 & Mesin tidak dapat mencapai putaran tinggi Mesin mati secara & 0,5 & 0,2 \\
atau bocor & G11 & perlahan pada saat mesin berputar & 0,8 & 0,2 \\
\hline $\begin{array}{l}\text { Kampas kopling } \\
\text { aus }\end{array}$ & G12 & Mesin tidak dapat berjalan & 0,7 & 0,2 \\
\hline
\end{tabular}


Perhitungan manual berdasarkan table Irisan

1. Analisa gejala G10 (mesin tidak dapat mencapai putaran tinggi ).tehadap kerusakan filter udara kotor

2. Di ket :

$\begin{array}{ll}\text { Kode gejala : G01 } & \\ \mathrm{MB}= & 0,6 \\ \mathrm{MD}= & 0,2 \\ \mathrm{CF}=\mathbf{M B}-\mathbf{M D} & \mathbf{0 , 4}\end{array}$

3. Analisa Gejala G10(mesin Tidak dapat mencapai putaran tinggi) ,G11 (Mesin mati secara perlahan) terhadap kerusakan filter bahan bakar bocor

Kode gejala : G10

MB Sementara $=$ MB Baru

MD Sementara $=$ MB Baru

Kode gejala : G11

MB Lama

MD Lama

MB Baru

MD Baru

MB Sementara

MD Sementara

Hasil

Nilai CF $=\quad \mathrm{MB}$ Sementara

$=\quad \mathrm{MD}$ Sementara

$=\mathrm{MB}$

$=\quad \mathrm{MD}$

$=$ MB Lama + $($ MB Baru * $(1-$ MB Lama $))$

$=\mathrm{MD} \mathrm{Lama}+(\mathrm{MD}$ Baru * $(1-\mathrm{MD}$ Lama $))$

$=$ MB Sementara - MD Sementara
$=0,5$

$=0,2$

$=0,5$

$=0,2$

$=0,5$

$=0,2$

$=0,8$

$=0,2$

$=0,9$

$=0,36$

$=0,54$

4. Analisa gejala G12 (Unit tidak bisa jalan) terhadap kerusakan kampas kopling aus atau Bocor.

Di ketahui:
Kode gejala : G12
$\mathrm{MB}=$
$\mathrm{MD}=$
(20)
$\mathrm{CF} \quad=\quad \mathbf{M B}-\mathbf{M D}$
0,7
$=\quad 0,2$
$\mathbf{0 , 5}$

Dari hasil perhitungan menggunakan metode certainty factor, bahwa truck tersebut mengalami filter bahan bakar kotor atau fuel line bocor dengan Nilai $\mathrm{CF}$ 0,54 untuk menangani kerusakan tersebut di tangani dengan solusi sebagai berikut:

1. Lakukan pembersihan filter bahan bakar di rekomendasikan ganti filter dengan yang baru

2. Repair hose fuel line atau ganti

3. Check tangki bahan bakar apabila kotoran di temukan pada filter yang baru

4. Kuras tangki bahan bakar

\section{KESIMPULAN}

Dengan adanya uji coba yang telah di lakukan maka dapat di ambil kesimpulan sebagai berikut:

1. Di bangunnya aplikasi Sistem pakar diagnose keruskan truk dutro maka dapat membantu mendeteksi lebih akurat dan cepat untuk mengetahui jenis kerusakan

2. Dengan dibangunnya aplikasi Sistem pakar diagnose keruskan truk dutro maka user dapat lebih cepat dan akurat dalam menangani kerusakan truk yang terjadi. 
3. Hasil nilai Penentuan bobot gejala diperoleh dari nilai interpretasi dan hasil wawancara kepada pakar.

4. Hasil nilai sistem yaitu $72,5 \%$ yang di dapat dari kepuasan para user dalam uji coba penggunaan sistem

5. Hasil Kuisioner dapat disimpulkan bahwa aplikasi dapat membantu mengetahui info truk dutro serta dapat membantu mendiagnosa kerusakan terhadap truck dutro.

\section{DAFTAR RUJUKAN}

[1] S. Kusrini, "Kom. Sistem Pakar, Teori dan Aplikasi," Penerbit Andi Yogyak., 2006.

[2] N. Irwan, "Aplikasi sistem pakar identifikasi penyakit pada tanaman padi menggunakan metode certainty factor," PhD Thesis, Universitas Islam Negeri Maulana Malik Ibrahim, 2016.

[3] H. E. Hutagaol, "PEMBANGUNAN SISTEM PAKAR DIAGNOSA PENYAKIT SAPI DENGAN METODE CERTAINTY FACTOR BERBASIS WEB," PhD Thesis, UAJY, 2015.

[4] S. Kusumadewi, "Artificial intelligence (teknik dan aplikasinya)," Yogyak. Graha Ilmu, vol. 278, 2003.

[5] H. Hamdani, H. Haviluddin, and M. S. Abdillah, "Sistem pendukung keputusan pembelian notebook menggunakan logika fuzzy tahani," Inform. Mulawarman J. Ilm. Ilmu Komput., vol. 6, no. 3, pp. 98-104, 2016.

[6] H. T. Sukaman, "Sistem pakar identifikasi bentuk keris jawa dengan metode CF (Certainty Factor)," 2011. 